Case report

\title{
Computed tomographic findings of tuberous sclerosis with pulmonary lymphangioleiomyomatosis and renal angiomyolipomas: a case report
}

\author{
Flavia Gavinho Vianna, Edson Marchiori*, Glaucia Zanetti, \\ Claudia Mauro Mano, Branca Sarcinelli-Luz, Juliana Franca Carvalho, \\ Carla Assed, Isabella Guedes Santos, Alair Augusto Santos and \\ Alberto Domingues Vianna
}

Address: Department of Radiology, Faculty of Medicine, Fluminense Federal University, CEP 25685.120, Petropolis Rio de Janeiro, Brazil

Email: FGV - flavinhavianna@yahoo.com.br; EM* - edmarchiori@gmail.com; GZ - glauciazanetti@gmail.com; CMM - cacaumano@gmail.com; BSL - brancaluz@gmail.com; JFC - fc.juliana@gmail.com; CA - carlassed@yahoo.com.br; IGS - isabella_guedess@yahoo.com.br; AAS - alair@microlink.com.br; ADV - albertodvianna@terra.com.br

* Corresponding author

Received: 14 January 2009 Accepted: 28 August 2009 Published: II September 2009

Cases Journal 2009, 2:9238 doi: 10.4076/1757-1626-2-9238

This article is available from: http://casesjournal.com/casesjournal/article/view/9238

(c) 2009 Vianna et al.; licensee Cases Network Ltd.

This is an Open Access article distributed under the terms of the Creative Commons Attribution License ( which permits unrestricted use, distribution, and reproduction in any medium, provided the original work is properly cited.

\begin{abstract}
The authors describe a case of a 31 -year-old female with tuberous sclerosis, a genetic, rare, variably expressed disease. Clinical symptoms were chest pain, and progressive dyspnea. Computed tomography scan of the chest showed bilateral, diffuse, small thin-walled cysts scattered throughout the lungs characteristic for pulmonary lymphangioleiomyomatosis. Computed tomography scan of the abdomen revealed enlarged, heterogeneous kidneys, with low density tumors corresponding to angiomyolipomas. Pulmonary lymphangioleiomyomatosis and bilateral renal angiomyolipomas are some presentations of tuberous sclerosis and the coexistence of both conditions may cause devastating morbidity and mortality.
\end{abstract}

\section{Introduction}

Tuberous sclerosis (TS) is an autosomal dominant disorder characterized by the formation of hamartomatous lesions in multiple organs, with a birth incidence of around one in 10,000 [1]. However, with more sensitive screening the prevalence may be as high as one in 6,000 $[2,3]$. The disease results from mutations in one of two genes, TSC1 (encoding hamartin) or TSC2 (encoding tuberin), which have an important role in the regulation of cell proliferation and differentiation [4]. Facial angiofibromas, renal angiomyolipomas, and pulmonary lymphangiomyomatosis (LAM) are some of the major features of this disease [4]. Diagnosis is usually established on the basis of physical examination, radiological findings or both, and the presentation of the disease varies substantially. We report a case of a female patient with TS presenting with pulmonary lymphangiomyomatosis and bilateral renal angiomyolipomas. 


\section{Case presentation}

A 31-year-old Caucasian Brazilian woman was admitted to the hospital with a 6-month history of chest pain and progressive dyspnea on exertion. She had angiofibromas on the malar regions of the face, which were present since her childhood. During her pregnancy, 11 years ago, she was diagnosed with polycystic kidney disease associated with tuberous sclerosis. She had repetitive urinary tract infections, which resulted in progressive loss of renal function. Both her grandfather and child had polycystic kidneys, and her son also presented seizures. The patient also had a history of hemorrhoidal disease causing intermittent bleeding.

On examination, the patient appeared pale, and her vital signs included a blood pressure of $120 / 80 \mathrm{mmHg}$ and a heart rate of $110 \mathrm{bpm}$. Auscultation revealed the presence of fine crackles in both lungs, and a loud systolic heart murmur was heard on the precordium. Her abdomen was tense and painful to palpation, but there were no signs of peritoneal irritation. There was a palpable mass occupying the upper abdomen and both flanks; Traube's space was obliterated. Laboratory evaluation revealed a red blood cell (RBC) count of $2.81 \times 10^{6} / \mathrm{mm}^{3}$, hemoglobin level of $9.0 \mathrm{~g} / \mathrm{dL}$, hematocrit of $27 \%$ and platelet count of $130 \times 10^{3} / \mathrm{mm}^{3}$. Her WBC count was normal. Serum creatinine was $3.3 \mathrm{mg} / \mathrm{dL}$; urea, $87 \mathrm{mg} / \mathrm{dL}$; glucose, $85 \mathrm{mg} / \mathrm{dL}$; sodium, $135 \mathrm{mEq} / \mathrm{L}$; potassium, $4.2 \mathrm{mEq} / \mathrm{L}$; uric acid $4.5 \mathrm{mg} / \mathrm{dL}$; albumin, $2.8 \mathrm{~g} / \mathrm{dL}$; calcium, $7.9 \mathrm{mg} / \mathrm{dL}$; phosphorus, $5.2 \mathrm{mg} / \mathrm{dL}$; and magnesium, $2.4 \mathrm{mg} / \mathrm{dL}$.

Chest computed tomography (CT) revealed cystic formations throughout the lungs, consistent with lymphangioleiomyomatosis (Figure 1), and the presence of a pericardial effusion. The echocardiogram showed a small pericardial effusion, and moderate left ventricular hypertrophy, and a normal systolic function. An abdominal CT scan demonstrated enlarged, heterogeneous kidneys, with multiple fat-density formations (negative densities, ranging from -15 to -148 Hounsfield units), which corresponded to angiomyolipomas (Figure 2). Pulmonary function tests showed a severe obstructive pulmonary disorder with reduced forced vital capacity, and a positive response to bronchodilator. She started treatment with medroxyprogesterone, and her respiratory status remained stable. An echocardiogram performed three years later revealed worsening of cardiac condition, enlargement of right cavities and left atrium, and thickening of the aortic valve leaflets; systolic function was preserved. Follow-up CT scans did not show significant changes.

\section{Discussion}

The benign, non-invasive lesions of tuberous sclerosis can appear in any organ like the brain, heart, skin, eyes, kidney, lung, and liver. Therefore, TS has a wide clinical

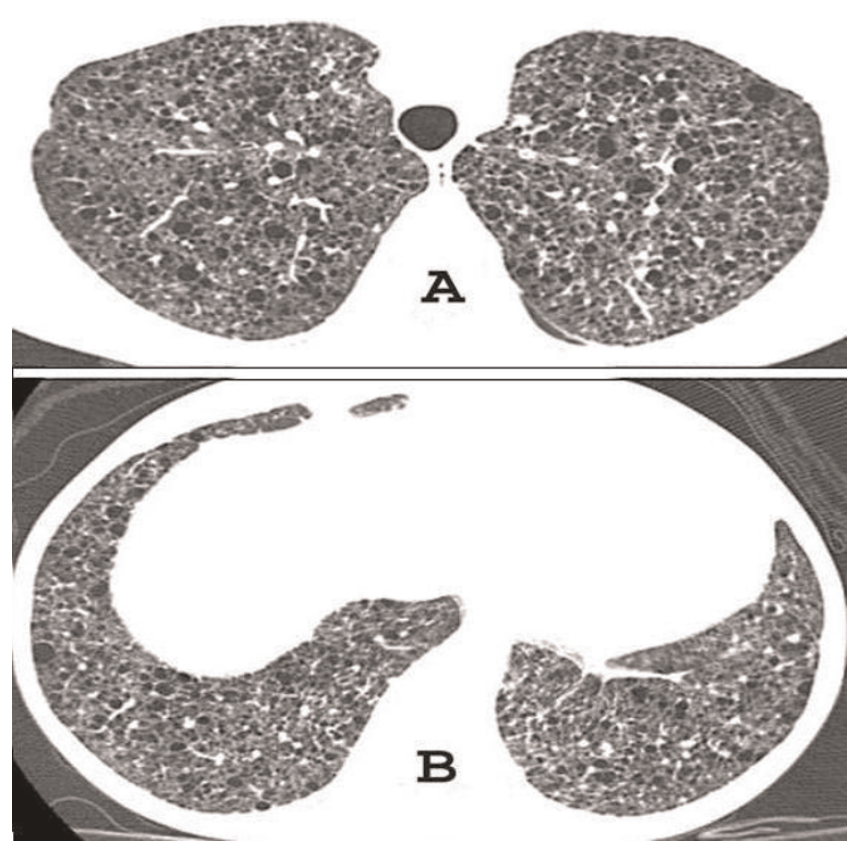

Figure I. High-resolution CT of the chest at the level of the upper (A) and lower lobes (B) shows well defined thin-walled cysts randomly scattered throughout both lungs.
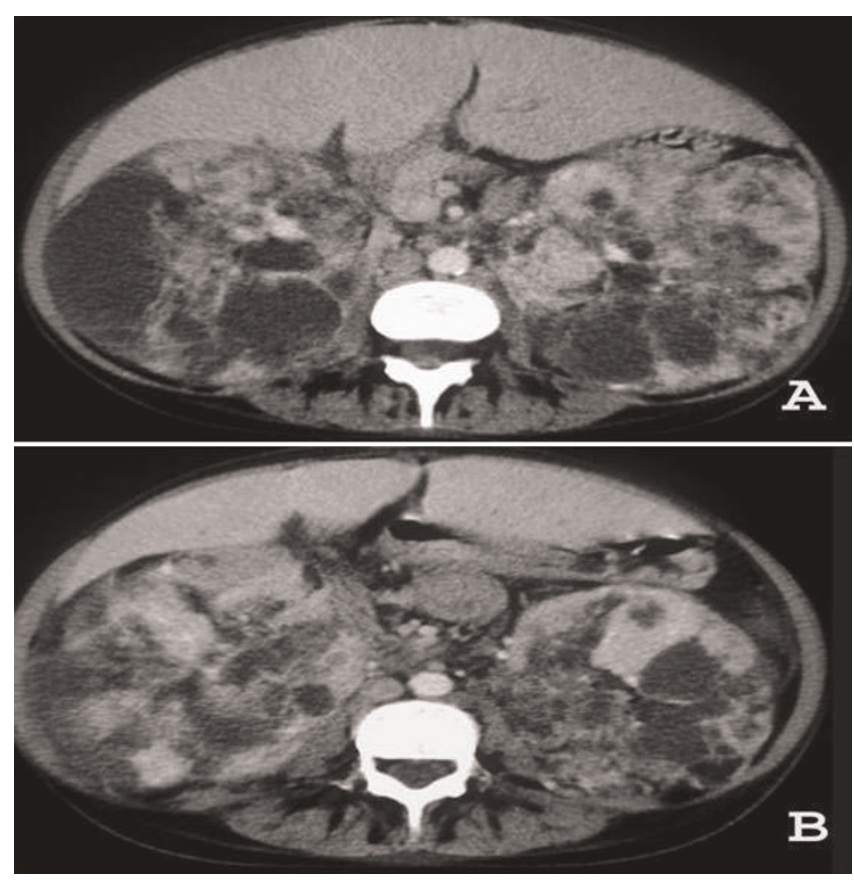

Figure 2. CT of the upper abdominal region demonstrates bilateral giant renal masses consisting predominantly of fat tissue. The density measurement of the hypodense content ranged from -15 to -148 Hounsfield units. 
spectrum. The diagnosis of definitive TS is based on specific clinical features and requires the presence of two major criteria, or one major and two minor [3]. Pulmonary lymphangioleiomyomatosis, renal angiomyolipoma and facial angiofibroma are some of the major clinical features.

The most frequent cause of death in patients with TS is renal complication $[3,5]$. Multifocal, bilateral angiomyolipomas are found in about $70-90 \%$ of adult patients [3], and the prevalence increases with age, being less frequent in children $[3,4]$. These lesions are more often prevalent in women, suggesting a hormonal component to the tumor growth [6]. The angiomyolipomas are composed of varying amounts of mature adipose tissue, smooth muscle, and abnormal blood vessels [3,6]. The demonstration of intratumoral fat with negative attenuation values at CT is virtually pathognomonic of angiomyolipoma. Thin-section unenhanced CT is essential to visualize the fat content of angiomyolipomas [7]. Progressive enlargement of tumors and hemorrhage into the lesion can result in flank pain, a palpable tender mass and gross or microscopic hematuria, and interfere with renal function [6]. Tumors larger than $4 \mathrm{~cm}$ in diameter have a greater risk of spontaneous or traumatic rupture resulting in hemorrhagic complications [6], which is the most common cause of death in patients with TS [8]. Some patients with TS carry a contiguous germline deletion that affects both the TSC2 gene and the adjacent gene, polycystic kidney disease type 1 (PKD1), resulting in a polycystic kidney phenotype that leads to early renal insufficiency $[3,4]$. In our patient, the family history indicates that she inherited a germline mutation in the TSC2 gene. Renal cell carcinoma can occur in approximately $2-3 \%$ of adults with TS [3].

Pulmonary LAM is a rare progressive disease that predominantly affects women of childbearing age. Estrogen is thought to play a role in disease progression since it does not present prior to menarche and only rarely after menopause [9], and is exceptionally rare in men $[1,3,8]$. LAM probably affects $1-3 \%$ of patients with tuberous sclerosis $[3,5]$. Although some articles report the occurrence of LAM in 1 to $3 \%$ of the patients with TS $[3,5]$, it seems that this incidence is much higher. Recent articles [10-12] report an incidence ranging from 26 to $34 \%$. It is characterized by alveolar smooth-muscle proliferation leading to air trapping, pulmonary hemorrhage and lymphatic extravasation, and cystic destruction of the normal lung parenchyma [3]. Some of the manifestations are shortness of breath, coughing, chest pain, pneumothorax, chylous pleural effusions, hemoptysis, and eventually respiratory failure, but asymptomatic cases may occur $[1,3,4]$. Pulmonary function tests can show an obstructive or restrictive pattern [1]. Classical CT findings (diffuse, homogeneous, small thin-walled cysts) and compatible clinical history can be highly suggestive of LAM [5]. It is extremely difficult to treat, and the long-term prognosis is poor with the average duration of survival from the time of diagnosis near to 10 years [1]. Treatment consists of supportive management; hormonal therapy has been tried but without consistent success [1,9]. Sirolimus (rapamycin) is being explored as another potential treatment, but additional trials will be needed to assess efficacy and potential side effects $[11,13]$.

Renal angiomyolipomas are present in 93\% of patients with tuberous-sclerosis-associated pulmonary lymphangiomyomatosis [3]. It is important to recognize LAM before renal surgery for angiomyolipoma because of the risk of spontaneous pneumothorax or other perioperative pulmonary complication [5,8]. Pneumothoraces ultimately occur in approximately 60 to $70 \%$ of patients with LAM, and the rate of recurrence is $>70 \%$, the highest among all chronic lung diseases [11].

Finally, it is very important to understand that a patient with TS requires a multidisciplinary clinical staff to receive a complete evaluation of the multisystem complications. In patients with lymphangiomyomatosis, annual pulmonaryfunction testing may be useful to monitor lung function and provide a measure of disease progression [4]. The monitoring of angiomyolipomas growth, by ultrasonography, CT, or magnetic resonance, is an essential issue in the management of TS [4].

\section{Abbreviations}

CT, computed tomography; LAM, lymphangiomyomatosis; TS, tuberous sclerosis.

\section{Consent}

Written informed consent was obtained from the patient for publication of this case report and accompanying images. A copy of the written consent is available for review by the Editor-in-Chief of this journal. Funding was neither sought nor obtained.

\section{Competing interests}

The authors declare that they have no competing interests.

\section{Authors' contributions}

FV conceived the study. BL, JC, CA and IS performed the literature review. FV, EM, GZ, CM, AS and AV edit and coordinated the manuscript. All authors read and approved the final manuscript.

\section{References}

I. Hancock E, Tomkins S, Sampson J, Osborne J: Lymphangioleiomyomatosis and tuberous sclerosis. Respir Med 2002, 96:7-I3.

2. Choyke PL, Glenn GM, Walther MM, Zbar B, Linehan WM: Hereditary renal cancers. Radiology 2003, 226:33-46. 
3. Curatolo P, Bombardieri R, Jozwiak S: Tuberous sclerosis. Lancet 2008, 372:657-668

4. Crino PB, Nathanson KL, Henske EP: The tuberous sclerosis complex. N Engl J Med 2006, 355: I 345-I 356

5. Tuzel E, Kirkali Z, Mungan U, Culer C, Sade M: Giant angiomyolipoma associated with marked pulmonary lesions suggesting lymphangioleiomyomatosis in a patient with tuberous sclerosis. Int Urol Nephrol 2000, 32:219-222.

6. Wright T, Sooriakumaran P: Renal angiomyolipoma presenting with massive retroperitoneal haemorrhage due to deranged clotting factors: a case report. Cases J 2008, I:213.

7. Prasad SR, Surabhi VR, Menias CO, Raut AA, Chintapalli KN: Benign renal neoplasms in adults: cross-sectional imaging findings. AJR Am J Roentgenol 2008, 190:158-164.

8. Yoshida S, Hayashi T, Ishii N, Yoshinaga A, Ohno R, Terao T, Watanabe $\mathrm{T}$, Yamada $\mathrm{T}$, Osada $\mathrm{H}$ : Bilateral renal angiomyolipoma coexistent with pulmonary lymphangioleiomyomatosis and tuberous sclerosis. Int Urol Nephrol 2006, 38:4I3-4I5.

9. Johnson SR, Tattersfield AE: Clinical experience of lymphangioleiomyomatosis in the UK. Thorax 2000, 55: 1052-1057.

10. Costello LC, Hartman TE, Ryu JH: High frequency of pulmonary lymphangioleiomyomatosis in women with tuberous sclerosis complex. Mayo Clin Proc 2000, 75:59I-594.

II. McCormack FX: Lymphangioleiomyomatosis: a clinical update. Chest 2008, I33:507-516.

12. Moss J, Avila NA, Barnes PM, Litzenberger RA, Bechtle J, Brooks PG, Hedin CJ, Hunsberger S, Kristof AS: Prevalence and clinical characteristics of lymphangioleiomyomatosis (LAM) in patients with tuberous sclerosis complex. Am J Respir Crit Care Med 200I, 164:669-67I.

13. Bissler JJ, McCormack FX, Young LR, Elwing JM, Chuck G, Leonard JM, Schmithorst VJ, Laor T, Brody AS, Bean J, Salisbury S, Franz DN: Sirolimus for angiomyolipoma in tuberous sclerosis complex or lymphangioleiomyomatosis. N Engl J Med 2008, 358: $|40-| 5 \mid$.

\section{Do you have a case to share?}

Submit your case report today

- Rapid peer review

- Fast publication

- PubMed indexing

- Inclusion in Cases Database

\section{Any patient, any case, can teach us something}

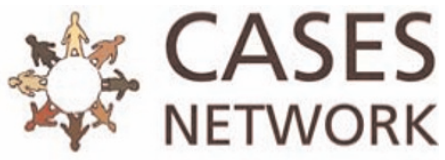

www.casesnetwork.com 